\title{
Association between apolipoprotein B genetic polymorphism and the risk of calcific aortic stenosis in Chinese subjects, in Xinjiang, China
}

Yong-Tao Wang ${ }^{1,2+}$, Yang Li $i^{1,2+}$, Yi-Tong Ma ${ }^{1,2^{*}}$, Yi-Ning Yang ${ }^{1,2}$, Xiang Ma ${ }^{1,2}$, Xiao-Mei $\mathrm{Li}^{1,2}$, Fen Liu ${ }^{2}$ and Bang-Dang Chen ${ }^{2}$

\begin{abstract}
Background: Limited information is available when it comes to the impact of genetic on Calcific Aortic Stenosis (CAS). Apolipoprotein B (apoB) is a key component in lipid metabolism and plays an important role in the dynamic equilibrium of cholesterol. We performed a case-control study to explore the association of apoB genetic polymorphisms with CAS in Chinese subjects, in Xinjiang, China.

Methods: We designed a case-control study including 314 CAS patients and 652 age- and sex-matched control subjects. Using the polymerase chain reaction-restriction fragment length (PCR-RFLP) method, we genotyped two SNPs (rs6725189 and rs693) of apoB gene in all subjects.

Results: We found that the rs693 T allele was associated with a significantly elevated CAS risk [T/CT vs. CC: adjusted odds ratio $(A O R)=1.58,95 \%$ confidence interval $(C I)=1.82-2.10, P=0.002$ ] and the rs6725189 $\mathrm{T}$ allele was also associated with a significantly elevated CAS risk (GT vs. GG: $A O R=1.82,95 \% \mathrm{Cl}=1.14-2.92, P=0.013$ ). Furthermore, we also found that the TC levels were significantly higher in rs693 T/CT genotypes than that in CC genotypes $(P<0.05)$.
\end{abstract}

Conclusions: Both rs693 and rs6725189 of the apoB gene are associated with CAS in Chinese subjects, in Xinjiang, China.

Keywords: apoB, Calcific aortic stenosis, Single nucleotide polymorphism

\section{Background}

With the increasing of elderly population and improvement of living standards, calcified valvular heart disease has outpaced rheumatic valvular disease to become the most common heart valve disease [1]. Calcific aortic stenosis (CAS), as the most common type of calcified valvular heart disease, is an important cause of increased morbidity and mortality [2-4]. The prevalence of CAS in adults older than 75 years is higher than $3 \%$ and the figure may double within the next 50 years $[5,6]$. Furthermore, CAS is also the most common indication for surgical valve

\footnotetext{
* Correspondence: myt_xj@sina.com

${ }^{\dagger}$ Equal contributors

'Department of Cardiology, First Affiliated Hospital of Xinjiang Medical University, Urumqi 830054, People's Republic of China

${ }^{2}$ Xinjiang Key Laboratory of Cardiovascular Disease Research, Urumqi 830054

People's Republic of China
}

replacement and transcatheter aortic valve implantation $[7,8]$. The high prevalence of CAS, together with its severe prognosis reveal it to be an increasing burden.

Apolipoprotein B (apoB) is a key structural component of all the atherogenic lipoproteins (LDL, very lowdensity lipoprotein (VLDL), intermediate-density lipoprotein (IDL) and lipoprotein a) and plays an important role in the dynamic equilibrium of cholesterol [9]. The Copenhagen City Heart Study is the first prospective study to estimate the predictive role of apoB in ischemic cardiovascular disease risk in the general population in both women and men. The results from this study showed that apoB was superior to LDL-C in the prediction of cardiovascular disease [10].

The apoB gene is located on the short arm of chromosome 2 and spans 43 kilobases, including 28 exons. 
Studies performed on twins indicated that genetic components account for $50-60 \%$ of the variation in plasma apoB levels [11]. In addition, several other studies have demonstrated that polymorphisms of the apoB gene are associated with atherosclerosis [12-14]. However, the association between apoB gene and CAS was still unclear. The present case-control study aimed to explore the association of apoB gene polymorphisms with CAS in Chinese subjects.

\section{Methods}

\section{Ethics statement}

This study was approved by the Ethics Committee of the First Affiliated Hospital of Xinjiang Medical University (Xinjiang, China). It was conducted according to the standards of the Declaration of Helsinki. Written informed consent was obtained from each participant, who explicitly provided permission for all DNA analyses and the collection of relevant clinical data.

\section{Subjects}

All of the participants were Han Chinese and were selected from the First Affiliated Hospital of Xinjiang Medical University. The time period of the study was from January 2012 to January 2016. A total of 314 subjects diagnosed with CAS and 652 health controls were recruited. CAS was defined as thickened and/or calcified aortic leaflets with restricted systolic motion, a calculated aortic valve area $1.8 \mathrm{~cm}^{2}$ and a transaortic mean pressure gradient $10 \mathrm{mmHg}[15,16]$. Subjects who did not have relevant valvular abnormalities in echocardiograms or a history of valvular heart disease were selected as the control group. Subjects with rheumatic heart disease, congenital heart disease, chronic kidney disease, and syphilitic heart disease were excluded. Hypertension was defined as self-reported use of antihypertensive medication within the past 2 weeks or an average systolic blood pressure $\geq 140 \mathrm{mmHg}$, an average diastolic blood pressure $\geq 90 \mathrm{mmHg}$, or both. Diabetes was defined as fasting plasma glucose $\geq 6.99 \mathrm{mmol} /$ $\mathrm{L}$, the use of insulin or oral hypoglycemic agents, or a selfreported history of diabetes. Smoking was defined as currently smoking cigarettes. We have added these to the method section.

\section{Biochemical analyses}

Blood samples were obtained from an antecubital vein into vacutainer tubes containing EDTA in the morning after an overnight fasting period. We measured the plasma concentration of blood triglyceride (TG), total cholesterol (TC), low density lipoprotein (LDL), high density lipoprotein (HDL) and fasting plasma glucose (FPG) in the Clinical Laboratory Department of the First Affiliated Hospital of Xinjiang Medical University [17, 18].

\section{APOB genotyping}

We selected two single-nucleotide polymorphisms (SNPs) in the human APOB gene as markers for assessment of genetic association. There are $5453 \mathrm{SNPs}$ for the human apoB gene listed in the National Center for Biotechnology Information SNP database (http://www.ncbi.nlm.nih.gov/ SNP). Using Haploview 4.2 software and International HapMap Project website phase I\&II data base (http://www.hapmap.org), we obtained two tagging SNPs (rs6725189,rs693) using minor allele frequency (MAF) $\geq 0.05$ and linkage disequilibrium patterns with $\mathrm{r} 2 \geq 0.8$ as a cutoff. Genomic DNA was extracted from peripheral blood leukocytes using a DNA extraction Kit (Beijing Bioteke Company Limited, Beijing, China). Genotyping in this present study was confirmed via polymerase chain reaction (PCR)-restriction fragment length polymorphism (RFLP) analysis. Sequencing primers were designed using Primer Premier 5.0 software. Synthesis of the Premier was undertaken by Shanghai Genery Biological Technology Company Limited (Shanghai, China). PCR amplification was performed using $25 \mu \mathrm{L}$ of 2*powder Taq PCR master mix (Beijing Biotech, Beijing, China), $50 \mathrm{ng}$ of genomic DNA, $21 \mu \mathrm{L}$ of distilled water, $1 \mu \mathrm{L}$ of each forward and reverse primer in a $50 \mu \mathrm{L}$ final reaction volume. The thermal cycling conditions were as follows: an initial denaturation step at $95{ }^{\circ} \mathrm{C}$ for $5 \mathrm{~min}$; 35 cycles of $95{ }^{\circ} \mathrm{C}$ for $30 \mathrm{~s}, 51.3{ }^{\circ} \mathrm{C}$ for $30 \mathrm{~s}$ and $72{ }^{\circ} \mathrm{C}$ for $45 \mathrm{~s}$ was followed by a final extension step of $72{ }^{\circ} \mathrm{C}$ for $10 \mathrm{~min}$. Thermal cycling was performed using the GeneAmp 9700 system (Applied Biosystems). Digestion of PCR products by restriction enzymes was conducted according to the manufacturer's instructions [19]. The primer pair sequences, annealing temperatures, resulting fragments and restriction enzymes for the two SNPs are detailed in Table 1. The digested products were analyzed on $3 \%$ agarose gels and stained with ethidium bromide (Fig. 1). In our test,

Table 1 The primer sequences for each SNP

\begin{tabular}{|c|c|c|c|c|}
\hline SNPS & Polymerase chain reaction primers & Denaturation temperature & Product length & Restriction enzyme \\
\hline \multirow[t]{2}{*}{ Rs6725189 } & Sense 5'TATTCCCTATTATGTTGTGG3' & $51.3^{\circ} \mathrm{C}$ & 788 & Ace I \\
\hline & Antisense 5'CTTGAAGGTGGACTGGTT 3' & & & \\
\hline \multirow[t]{2}{*}{ Rs693 } & Sense 5'GGAAAGCCTACAGGACAC3' & $51.3^{\circ} \mathrm{C}$ & 290 & FnuA I \\
\hline & Antisense 5'TCATACGTTTAGCCCAAT3' & & & \\
\hline
\end{tabular}




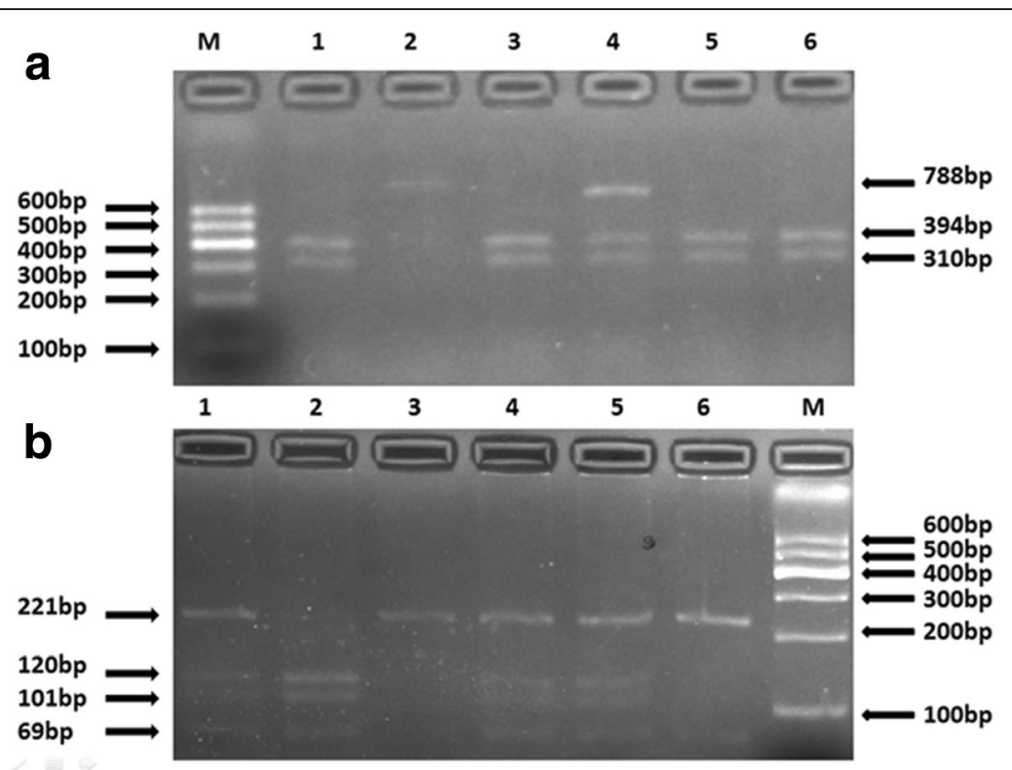

Fig. 1 The restriction fragment length polymorphism analysis to determine the genotype. a. For rs6725189, the $\Pi$ genotype shows two bands at $788 \mathrm{bp}$ and $84 \mathrm{bp}(2)$; the GG genotype shows three bands at $394 \mathrm{bp}, 310 \mathrm{bp}$ and $84 \mathrm{bp}$ (1, 3, 5 and 6); and the GT genotype shows four bands at 788 bp, 394 bp, 310 bp and 84 bp (4). b. For rs693, the CC genotype shows two bands at 221 bp and $69 \mathrm{bp}$ (3 and 6); the Tा genotype shows three bands at $120 \mathrm{bp}, 101 \mathrm{bp}$ and $69 \mathrm{bp}$ (2); and the CT genotype shows four bands at $221 \mathrm{bp}, 120 \mathrm{bp}, 101 \mathrm{bp}$ and $69 \mathrm{bp}(1,4$ and 5)

there exist at least one positive and one negative control per 96 -well DNA plate and we also duplicated $10 \%$ of the total genotyped samples. The rate of genotyping success for each SNP was $100 \%$.

\section{Statistical analysis}

Data analysis was performed using SPSS version 17.0 for Windows (SPSS Inc., Chicago, IL, USA). Hardy-Weinberg equilibrium was assessed via chi-square analysis. Measurement data are shown as the mean $\pm \mathrm{SD}$, and the differences between CAS and control subjects were assessed using independent-sample t-test. Differences in enumeration data such as frequencies of smoking, drinking, hypertension and apoB genotypes between the CAS and control subjects were analyzed using the chi-square test. Additionally, logistic regression analyses with effect ratios (odds ratio [OR] and 95\% CI) were used to assess contribution of major risk factors. $P$ value $<0.05$ was considered statistically significant.

\section{Result}

\section{Characteristics of subjects}

The baseline characteristics of 314 CAS patients and 652 control subjects were shown in Table 2. The mean age, male to female ratio, BMI, TG and HDL-C levels were similar between the controls and CAS patients (all $P>$ 0.05). The SBP, DBP, glucose, TC, LDL-C levels and the percentages of subjects who have hypertension, diabetes and smoke were significantly higher in the CAS patients than in the controls (all $P<0.05$ ).

\section{Distributions of genotype and allele in patients with valvular calcification and controls}

Table 3 shows the distribution of genotypes and alleles for the two SNPs (rs6725189 and rs693) of the apoB gene. The genotype distributions of the two SNPs were in accordance with the Hardy-Weinberg equilibrium in

Table 2 Clinical and metabolic characteristics of subjects

\begin{tabular}{llll}
\hline Characteristic & Control $(n=652)$ & Case $(n=314)$ & $P$ value \\
\hline Age(years) & $67.69 \pm 8.85$ & $67.39 \pm 9.76$ & 0.633 \\
Male/female & $360 / 292$ & $158 / 156$ & 0.153 \\
BMI(kg/m²) & $25.91 \pm 3.90$ & $26.17 \pm 4.13$ & 0.344 \\
SBP $(\mathrm{mmHg})$ & $141.25 \pm 20.83$ & $149.69 \pm 25.64$ & $<0.001$ \\
DBP $(\mathrm{mmHg})$ & $86.49 \pm 16.25$ & $92.78 \pm 20.86$ & $<0.001$ \\
Hypertension(\%) & $333(51.1)$ & $213(67.8)$ & $<0.001$ \\
Diabetes(\%) & $50(7.7)$ & $41(13.1)$ & 0.007 \\
Smoking(\%) & $141(21.6)$ & $98(31.2)$ & 0.001 \\
Glucose $(\mathrm{mmol} / \mathrm{L})$ & $5.21 \pm 1.56$ & $5.51 \pm 2.02$ & 0.011 \\
$\mathrm{TC}(\mathrm{mmol} / \mathrm{L})$ & $4.60 \pm 1.11$ & $4.84 \pm 1.14$ & 0.002 \\
TG $(\mathrm{mmol} / \mathrm{L})$ & $1.52 \pm 1.15$ & $1.51 \pm 1.05$ & 0.915 \\
LDL-C(mmol/L) & $2.71 \pm 0.88$ & $2.97 \pm 0.99$ & $<0.001$ \\
HDL-C(mmol/L) & $1.26 \pm 0.49$ & $1.26 \pm 0.45$ & 0.939
\end{tabular}

Continuous variables are expressed as mean \pm SD. Categori cal variables are expressed as percentag es

The $P$ value of the continuous variables was calculated by the independent samples t test. The $P$ value of the categorical variables was calculated by $\mathrm{X} 2$ test

TG triglyceride, $T C$ total cholesterol, $H D L-C$ high density lipoprotein-cholesterol, $L D L-C$ low density lipoprotein-cholesterol 
Table 3 Distribution of SNPs of apoB gene in CAS and controls

\begin{tabular}{|c|c|c|c|}
\hline Genotype or allele & Control[n(\%)] & CAS[n(\%)] & $P$ value \\
\hline \multicolumn{4}{|l|}{ rs693 } \\
\hline $\mathrm{CC}$ & $430(66.0)$ & 172(54.8) & \\
\hline CT & 150(23.0) & $95(30.2)$ & \\
\hline$\pi$ & $72(11.0)$ & $47(15.0)$ & 0.004 \\
\hline \multicolumn{4}{|l|}{ Dominant } \\
\hline$\pi+C T$ & $222(34.0)$ & $142(45.2)$ & \\
\hline $\mathrm{CC}$ & $430(66.0)$ & $172(54.8)$ & 0.001 \\
\hline \multicolumn{4}{|l|}{ Recessive } \\
\hline$\pi$ & $72(11.0)$ & $47(15.0)$ & \\
\hline$C C+C T$ & $580(89.0)$ & $267(85.0)$ & 0.082 \\
\hline \multicolumn{4}{|l|}{ Additive } \\
\hline $\mathrm{CT}$ & 150(23.0) & $95(30.2)$ & \\
\hline$C C+\pi$ & $502(77.0)$ & 219(69.8) & 0.015 \\
\hline \multicolumn{4}{|l|}{ Allele } \\
\hline C & 1010(77.5) & 439(69.9) & \\
\hline $\mathrm{T}$ & $294(22.5)$ & 189(30.1) & $<0.001$ \\
\hline \multicolumn{4}{|l|}{ rs6725189 } \\
\hline GG & 589(90.3) & $270(86.0)$ & \\
\hline GT & $63(9.7)$ & $44(14.0)$ & 0.044 \\
\hline \multicolumn{4}{|l|}{ Allele } \\
\hline G & $1241(95.2)$ & $584(93.0)$ & \\
\hline T & $63(4.8)$ & $44(7.0)$ & 0.051 \\
\hline
\end{tabular}

controls (all $P>0.05$ ). For rs693, the distribution of the genotypes, the dominant model (TT $+\mathrm{CT}$ vs $\mathrm{CC})$, the additive model (CT vs CC + TT) and the allele frequency showed significant differences between the controls and CAS patients $(P=0.004, P=0.001, P=0.015, P<0.001$, respectively). For rs6725189, the distribution of the genotypes showed significant differences between the controls and CAS patients $(P=0.044)$.

\section{Stratified analysis between apoB gene polymorphisms and CAS risk}

We performed stratifcation analyses in terms of gender, hypertension, diabetes and smoking status to evaluate how these variables modifed the association between the SNPs (rs693 and rs6725189) and CAS risk (Table 4). Multiple logistic regression were used to adjust confounding factors. For female, the dominant model (TT + CT vs CC) of rs693 remain significantly associated with CAS $(\mathrm{OR}=1.89,95 \% \mathrm{CI}=1.27-2.81, P=0.002)$. For male and female, rs6725189 remain significantly associated with CAS (male: $\mathrm{OR}=1.59,95 \% \mathrm{CI}=1.04-2.43, P$ $=0.032$; female: $\mathrm{OR}=1.69,95 \% \mathrm{CI}=1.14-2.52, \quad P=$ 0.010). For subgroup with hypertension, the dominant model (TT $+\mathrm{CT}$ vs CC) of rs693 remain significantly associated with CAS $(\mathrm{OR}=1.54,95 \% \mathrm{CI}=1.07-2.23, P=$
0.020). For subgroup with and without hypertension, rs6725189 remain significantly associated with CAS (subgroup with hypertension: $\mathrm{OR}=1.57,95 \% \mathrm{CI}=1.09$ $2.27, P=0.015$; subgroup without hypertension: OR $=1.70,95 \% \mathrm{CI}=1.05-2.76, \quad P=0.031)$. For subgroup without diabetes, the dominant model ( TT $+\mathrm{CT}$ vs $\mathrm{CC})$ of rs693 remain significantly associated with CAS (OR = 1.52 , 95\% $\mathrm{CI}=1.12-2.06, P=0.007)$. For subgroup with diabetes, rs6725189 remain significantly associated with CAS $(\mathrm{OR}=1.67,95 \% \mathrm{CI}=1.23-2.26, P=0.001)$. For nonsmoker and smoker, the dominant model (TT + CT vs CC) of rs693 and rs6725189 remain significantly associated with CAS(rs693: nonsmoker: $\mathrm{OR}=1.41,95 \% \mathrm{CI}=$ 1.01-1.97, $P=0.046$, smoker: $\mathrm{OR}=2.16,95 \% \mathrm{CI}=1.21$ 3.88, $P=0.010$; rs6715189: nonsmoker: $\mathrm{OR}=1.44$, $95 \%$ $\mathrm{CI}=1.03-2.02, P=0.032$, smoker: $\mathrm{OR}=2.51,95 \% \mathrm{CI}=$ 1.39-4.53, $P=0.002$ ).

\section{Related risk factors for CAS}

Multivariate logistic analysis was used to assess contribution of major risk factors in the whole sample which contains all 966 participants. Multiple logistic regression showed that the incidence of CAS positively correlated with hypertension, diabetes, smoking, TC, LDL-C, rs693 TT/CT genotypes and rs6725189 GT genotypes (Tables 5 and 6).

\section{Genotypes and serum lipid levels}

As shown in Fig. 2, the TC levels were significantly higher in rs693 TT/CT genotypes than that in CC genotypes $(P<0.05)$.

\section{Discussion}

In this investigation of apoB alleles and CAS, we found that variation in the apoB gene is associated with CAS. To date, this is the first study to investigate the association between the human apoB gene and CAS in Chinese subjects, in Xinjiang, China.

Although development of CAS is likely to occur among members of a family [20], and several studies have reported relationships between gene and CAS [21-23], knowledge of the role of genomic predictive markers in CAS remains elusive. CAS appears to be active and involves a chronic inflammatory infiltrate with lipid and lipoprotein deposition, including apoB and LDL $[4,5,8]$. It has been suggested that CAS is a manifestation of generalized atherosclerosis, with similar pathogenesis and common risk factors. Whether the initiation of CAS has a genetic contribution as atherosclerosis is unknown. The first investigation of the association of gene polymorphisms with CAS was carried out in 2001 by Ortlepp et al. [24]. They hypothesized that the gene encoding vitamin $\mathrm{D}$ receptor (VDR) may correlate with CAS and identified that the B allele of rs 1544410 is a risk factor. Several studies have demonstrated that not only 
Table 4 Stratifed analysis between apoB gene polymorphisms and CAS risk

\begin{tabular}{|c|c|c|c|c|c|c|c|}
\hline & Case/control & rs693 (Genetype) & Adjusted OR (95\% Cl) & $P$ value & rs6725189 (Genetype) & Adjusted OR (95\% Cl) & $P$ value \\
\hline \multicolumn{8}{|l|}{ Gender } \\
\hline Male & $158 / 360$ & $\pi+C T / C C$ & 1.295(0.848-1.977) & 0.232 & GT/GG & $1.592(1.042-2.433)$ & 0.032 \\
\hline Female & $156 / 292$ & $\Pi+\mathrm{CT} / \mathrm{CC}$ & $1.888(1.266-2.814)$ & 0.002 & GT/GG & $1.689(1.135-2.515)$ & 0.01 \\
\hline \multicolumn{8}{|l|}{ Hypertension } \\
\hline No & $101 / 319$ & $\Pi+\mathrm{CT} / \mathrm{CC}$ & $1.563(0.961-2.541)$ & 0.072 & GT/GG & $1.701(1.049-2.757)$ & 0.031 \\
\hline Yes & $213 / 333$ & $\pi+C T / C C$ & $1.544(1.071-2.226)$ & 0.02 & GT/GG & $1.574(1.092-2.271)$ & 0.015 \\
\hline \multicolumn{8}{|l|}{ Diabetes } \\
\hline No & $273 / 602$ & $T+C T / C C$ & $1.521(1.121-2.064)$ & 0.007 & GT/GG & $1.668(1.230-2.263)$ & 0.001 \\
\hline Yes & $41 / 50$ & $T+C T / C C$ & $1.854(0.714-4.814)$ & 0.205 & GT/GG & $1.221(0.474-3.143)$ & 0.679 \\
\hline \multicolumn{8}{|l|}{ Smoking } \\
\hline Nonsmoker & $216 / 511$ & $\Pi+C T / C C$ & $1.407(1.005-1.969)$ & 0.046 & GT/GG & $1.444(1.032-2.021)$ & 0.032 \\
\hline Smoker & $98 / 141$ & $\Pi+\mathrm{CT} / \mathrm{CC}$ & $2.163(1.206-3.877)$ & 0.01 & GT/GG & $2.509(1.390-4.527)$ & 0.002 \\
\hline
\end{tabular}

clinical atherosclerotic risk factors but also genetic predisposition, are required for the genesis of CAS [20, 22, 25].

In previous studies, we found that the apoB gene was associated with IMT, LDL level, and ABI, which is involved in atherosclerosis and CAS [9]. Similarly, apoB gene polymorphisms may also be a significant independent predictor of CAS. Research on the relationship between polymorphisms of apoB gene and CAS was first reported by Avakian et al., who demonstrated that the $\mathrm{X}$ $+\mathrm{X}+$ genotype polymorphism of the apoB gene (rs693) may be a risk factor for CAS $(24.0 \%$ in cases, $6 \%$ in controls, $P=0.00)$ in the Brazilian population [22]. Interestingly, both large-scale case-control study and genomewide association studies (GWAS) for lipid levels recently reported that the rs693 polymorphism was associated with cholesterol and triglyceride levels, which were risk factors for CAS in European populations [26, 27]. However, in a comprehensive replication study carried out by Gaudreault et al. in French Canadians, the rs693 polymorphism was demonstrated to have no correlation with CAS [20]. In contrast, two other SNPs (rs1042031 and

Table 5 Results of Logistic analysis (rs6725189)

\begin{tabular}{llll}
\hline Variables & OR & $95 \% \mathrm{Cl}$ & $P$ value \\
\hline rs6725189(GT vs.GG) & 1.819 & $1.135-2.916$ & 0.013 \\
Gender & 1.023 & $0.740-1.416$ & 0.888 \\
Age & 0.994 & $0.978-1.009$ & 0.425 \\
BMI & 0.988 & $0.953-1.025$ & 0.536 \\
Hypertension & 2.294 & $1.683-3.127$ & $<0.001$ \\
TG & 0.923 & $0.802-1.063$ & 0.266 \\
TC & 1.21 & $1.061-1.380$ & 0.005 \\
HDL-C & 0.855 & $0.623-1.174$ & 0.333 \\
LDL-C & 1.393 & $1.192-1.628$ & $<0.001$ \\
Diabetes & 1.514 & $0.923-2.483$ & 0.1 \\
Smoking & 1.822 & $1.268-2.618$ & 0.001 \\
\hline
\end{tabular}

rs6725189) of the apoB gene were significantly associated with CAS [20]. From the above example, we have considered that the association between apoB gene and CAS was different on account of polymorphisms of the apoB gene and ethnic differences.

In the present study, we genotyped polymorphisms of rs693 and rs6725189 SNPs in the apoB gene and found associations with CAS. We found that the rs693 CT/TT genotype and the rs6725189 GT genotype have a higher frequency in CAS patients than that in controls. After adjustments for several confounders, this association remained exist, indicating that the rs693 CT/TT genotype and the rs6725189 GT genotype were independent risk factors for CAS and the risk of CAS was increased in the subjects with the T allele in rs693 and rs6725189. Furthermore, we investigated the relationships between rs693 and rs6725189 and the plasma TC, TG, HDL-C and LDL-C levels. We found that T allele $(\mathrm{CT}+\mathrm{TT})$ carriers in rs693 have higher levels of TC when compared to $\mathrm{T}$ allele non-carriers. These results might provide convincing evidence for assuming subjects who carry $\mathrm{T}$

Table 6 Results of Logistic analysis (rs693)

\begin{tabular}{llll}
\hline Variables & OR & $95 \% \mathrm{Cl}$ & $P$ value \\
\hline rs693(CT + TT vs. CC) & 1.577 & $1.182-2.103$ & 0.002 \\
Gender & 0.998 & $0.722-1.379$ & 0.989 \\
Age & 0.995 & $0.980-1.011$ & 0.576 \\
BMl & 0.987 & $0.952-1.024$ & 0.495 \\
Hypertension & 2.147 & $1.583-2.911$ & $<0.001$ \\
TG & 0.928 & $0.806-1.069$ & 0.301 \\
TC & 1.191 & $1.044-1.359$ & 0.009 \\
HDL-C & 0.872 & $0.635-1.198$ & 0.399 \\
LDL-C & 1.387 & $1.187-1.621$ & $<0.001$ \\
Diabetes & 1.846 & $1.155-2.950$ & 0.01 \\
Smoking & 1.798 & $1.252-2.581$ & 0.001 \\
\hline
\end{tabular}



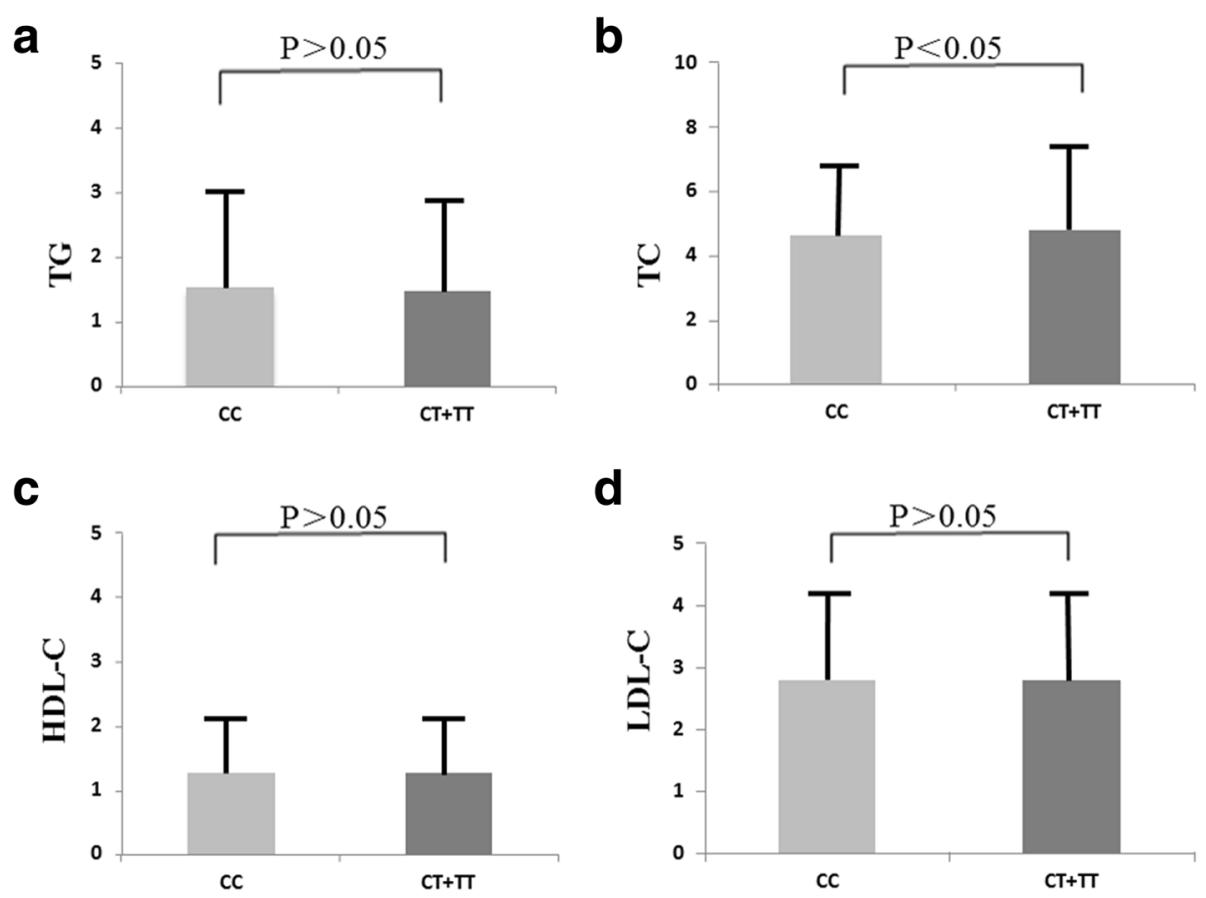

Fig. 2 Association between rs693 and lipid parameters. a. There exists no significant difference of TG between rs693 TT/CT genotypes and CC genotypes $(P>0.05)$; b. The TC levels were significantly higher in rs693 TT/CT genotypes than that in CC genotypes $(P<0.05)$; $\mathbf{c}$. There exists no significant difference of HDL-C between rs693 TT/CT genotypes and CC genotypes $(P>0.05)$; $\mathbf{d}$. There exists no significant difference of LDL-between rs693 TT/CT genotypes and CC genotypes $(P>0.05)$

allele in rs693 may have higher probabilities of suffering from CAS than that who carry $\mathrm{C}$ allele.

It remains a challenge to describe the mechanisms that link apoB genetic polymorphisms to CAS. ApoB gene polymorphisms have been suggested to be associated with atherosclerosis $[9,13,14]$. A likely explanation for this may be as follows: first, the various apoB genotypes are associated with divergent effects on plasma lipids: apoB and twin studies suggest that $50-60 \%$ of the variation in plasma levels of apoB is genetically determined [11]; second, apoB has been demonstrated to be a better estimation of the total number of atherogenic particles (including LDL, IDL, VLDL, chylomicrons, and chylomicron remnants) than LDL-C, as each atherogenic lipoprotein particle contains one apoB-100 molecule [9, 2830]; finally, several studies have shown that atherosclerosis may be more directly related to the total number of circulating atherogenic particles entering the arterial wall instead of the concentration of cholesterol in LDL particles, which were widely used for screening to identify individuals at risk for atherosclerosis [9, 31, 32]. Due to the similarity between CAS and atherosclerosis, the apoB gene may also effect the initiation of CAS.

Despite the promising findings in this study, some inherent limitations of this case-control study must be noted. First of all, due to the transversal character of the present study, we failed to get a cause-and-effect relationship between risk factors and CAS. Secondly, the sample size is small and large-scale studies are needed to verify these findings. Finally, the present study lacked functional validation. Additional studies need to be undertaken to clarify the underlying molecular mechanism that associates the apoB gene polymorphisms with CAS.

\section{Conclusion}

This study revealed that both rs693 and rs6725189 of the apoB gene are associated with CAS in Chinese subjects. Subjects with TT/CT genotype or T allele of rs693 and TT genotype or T allele of rs6725189 were associated with an increased risk of CAS. The TT/CT genotypes of rs693 were also associated with increased serum TC levels.

\section{Abbreviations}

apoB: Apolipoprotein B; GWAS: Genome-wide association studies; HDL-C: High density lipoprotein; IDL: Intermediate-density lipoprotein; LDL-C: Low density lipoprotein; SNPs: Single-nucleotide polymorphisms; TC: Total cholesterol;

TG: Triglyceride; VDR: Vitamin D receptor; VLDL: Very low-density lipoprotein

\section{Acknowledgements}

This work was supported financially by The science and technology support project Xinjiang Uygur Autonomous Region(2017E0269). 


\section{Availability of data and materials}

All data generated or analyzed during this study are included in this published article.

\section{Funding}

This work was supported financially by The science and technology support project Xinjiang Uygur Autonomous Region(2017E0269).

\section{Authors' contributions}

Conceived and designed the experiments: YTW, YL, YTM; Performed the experiments: YTW, YL; Analyzed the data: XML, FL, XM; Contributed reagents/ materials/analysis tools: YNY, BDC. Wrote the paper: YTW. All authors read and approved the final manuscript.

\section{Ethics approval and consent to participate}

This study was approved by the Ethics Committee of the First Affiliated Hospital of Xinjiang Medical University (Xinjiang, China). It was conducted according to the standards of the Declaration of Helsinki. Written informed consent was obtained from each participants, who explicitly provided permission for all DNA analyses and the collection of relevant clinical data.

\section{Consent for publication}

Not applicable.

\section{Competing interests}

The authors declare that they have no competing interests.

\section{Publisher's Note}

Springer Nature remains neutral with regard to jurisdictional claims in published maps and institutional affiliations.

\section{Received: 5 December 2017 Accepted: 2 March 2018}

\section{Published online: 07 March 2018}

\section{References}

1. Nkomo VT, Gardin JM, Skelton TN, Gottdiener JS, Scott CG, Enriquez-Sarano M. Burden of valvular heart diseases: a population-based study. Lancet. 2006:368:1005-11.

2. Gohlke-Bärwolf C, Minners J, Jander N, Gerdts E, Wachtell K, Ray S, et al. Natural history of mild and of moderate aortic stenosis-new insights from a large prospective European study. Curr Probl Cardiol. 2013;38(9):365-409.

3. Otto CM, Lind BK, Kitzman DW, Gersh BJ, Siscovick DS. Association of aorticvalve sclerosis with cardiovascular mortality and morbidity in the elderly. N Engl J Med. 1999;341:142-7.

4. Yutzey KE, Demer LL, Body SC, Huggins GS, Towler DA, Giachelli CM, et al. Calcific aortic valve disease: a consensus summary from the Alliance of Investigators on Calcific Aortic Valve Disease. Arterioscler Thromb Vasc Biol. 2014;34(11):2387-93.

5. lung B, Vahanian A. Degenerative calcifc aortic stenosis: a natural history. Heart. 2012;98(Suppl 4):iv7-13.

6. Bonow RO, Leon MB, Doshi D, Moat N. Management strategies and future challenges for aortic valve disease. Lancet. 2016;387(10025):1312-23.

7. Passik CS, Ackermann DM, Pluth JR, Edwards WD. Temporal changes in the causes of aortic stenosis: a surgical pathologic study of 646 cases. Mayo Clin Proc. 1987;62:119-23.

8. Lindman BR, Clavel MA, Mathieu P, lung B, Lancellotti P, Otto CM, et al. Calcific aortic stenosis. Nat Rev Dis Primers. 2016;2:16006.

9. Benn M. Apolipoprotein B levels, APOB alleles, and risk of ischemic cardiovascular disease in the general population, a review. Atherosclerosis. 2009:206:17-30

10. Benn M, Nordestgaard BG, Jensen GB, Tybjaerg-Hansen A. Improving prediction of ischemic cardiovascular disease in the general population using apolipoprotein B: the Copenhagen City heart study. Arterioscler Thromb Vasc Biol. 2007;27:661-70.

11. Beekman M, Heijmans BT, Martin NG, Pedersen NL, Whitfield JB, DeFaire U, et al. Heritabilities of apolipoprotein and lipid levels in three countries. Twin Res. 2002;5:87-97.

12. Tybjaerg-Hansen A. Rare and common mutations in hyperlipidemia and atherosclerosis with special reference to familial defective apolipoprotein B100. Scand J Clin Lab Invest Suppl. 1995;220:57-76.
13. Tybjaerg-Hansen A, Humphries SE. Familial defective apolipoprotein B-100: a single mutation that causes hypercholesterolemia and premature coronary artery disease. Atherosclerosis. 1992;96:91-107.

14. Kravchenko NA. The relationship of apoB gene polymorphism to dyslipoproteinemia as the cause of atherosclerosis. Tsitol Genet. 1995;29:84-7.

15. Skjaerpe $T$, Hegrenaes $L$, Hatle $L$. Noninvasive estimation of valve area in patients with aortic stenosis by Doppler ultrasound and twodimensional echocardiography. Circulation. 1985;72:810-8.

16. Novaro GM, Sachar R, Pearce GL, Sprecher DL, Griffin BP. Association between apolipoprotein $\mathrm{E}$ alleles and calcific valvular heart disease. Circulation. 2003:108(15):1804-8.

17. Xie X, Ma YT, Yang YN, Fu ZY, Li XM, Huang D, et al. Polymorphisms in the $S A A 1 / 2$ gene are associated with carotid intima media thickness in healthy Han Chinese subjects: the cardiovascular risk survey. PLoS One. 2010:5:e13997.

18. Wang Y-T, Wang Y-H, Ma Y-T, Fu Z-Y, Yang Y-N, Ma X, et al. ACAT-1 gene polymorphism is associated with increased susceptibility to coronary artery disease in Chinese Han population: a case-control study. Oncotarget. 2017; 8(51):89055-63.

19. Wang YT, Adi D, Yu ZX, Ma YT, Yang YN, Li XM, et al. The burden and correlates of hypertension among Chinese rural population in Han, Uygur, and Kazak: a cross-sectional study. J Am Soc Hypertens. 2017;11(11):737-45.

20. Gaudreault N, Ducharme V, Lamontagne M, Guauque-Olarte S, Mathieu P, Pibarot $\mathrm{P}$, et al. Replication of genetic association studies in aortic stenosis in adults. Am J Cardiol. 2011;108:1305-10.

21. Nordstrom P, Glader CA, Dahlen G, Birgander LS, Lorentzon R, Waldenstrom $A$, et al. Oestrogen receptor alpha gene polymorphism is related to aortic valve sclerosis in postmenopausal women. J Intern Med. 2003;254:140-6.

22. Avakian SD, Annicchino-Bizzacchi JM, Grinberg M, Ramires JA, Mansura AP. Apolipoproteins Al, B, and E polymorphisms in severe aortic valve stenosis. Clin Genet. 2001:60:381-4.

23. Kutikhin AG, Yuzhalin AE, Brusina EB, Ponasenko AV, Golovkin AS, Barbarash OL. Genetic predisposition to calcific aortic stenosis and mitral annular calcification. Mol Biol Rep. 2014;41:5645-63.

24. Ortlepp JR, Hoffmann R, Ohme F, Lauscher J, Bleckmann F, Hanrath P. The vitamin $D$ receptor genotype predisposes to the development of calcific aortic valve stenosis. Heart. 2001:85:635-8.

25. Thanassoulis G, Campbell CY, Owens DS, Smith JG, Smith AV, Peloso GM, et al. Genetic associations with valvular calcification and aortic stenosis. N Engl J Med. 2013;368:503-12.

26. Benn M, Nordestgaard BG, Jensen JS, Grande P, Sillesen H, Tybjaerg-Hansen A. Polymorphism in APOB associated with increased low-density lipoprotein levels in both genders in the general population. J Clin Endocrinol Metab. 2005:90:5797-803.

27. Johansen $C T$, Kathiresan $S$, Hegele RA. Genetic determinants of plasma triglycerides. J Lipid Res. 2011;52:189-206.

28. Talmud PJ, Hawe E, Miller GJ, Humphries SE. Nonfasting apolipoprotein B and triglyceride levels as a useful predictor of coronary heart disease risk in middle-aged UK men. Arterioscler Thromb Vasc Biol. 2002;22:1918-23.

29. St-Pierre AC, Cantin B, Dagenais GR, Despres JP, Lamarche B. Apolipoprotein-B, low-density lipoprotein cholesterol, and the long-term risk of coronary heart disease in men. Am J Cardiol. 2006;97:997-1001.

30. Chien KL, Hsu HC, Su TC, Chen MF, Lee YT, Hu FB. Apolipoprotein B and non-high density lipoprotein cholesterol and the risk of coronary heart disease in Chinese. J Lipid Res. 2007:48:2499-505.

31. McQueen MJ, Hawken S, Wang X, Ounpuu S, Sniderman A, Probstfield J, et al. Lipids, lipoproteins, and apolipoproteins as risk markers of myocardia infarction in 52 countries (the INTERHEART study): a case-control study. Lancet. 2008:372:224-33.

32. Ingelsson E, Schaefer EJ, Contois JH, McNamara JR, Sullivan L, Keyes MJ, et al. Clinical utility of different lipid measures for prediction of coronary heart disease in men and women. JAMA. 2007;298:776-85. 